\title{
Changes in astigmatism between the ages of 1 and 4 years: a longitudinal study
}

\author{
M ABRAHAMSSON,' G FABIAN, ' AND J SJÖSTRAND' \\ 'From the Department of Ophthalmology, University of Göteborg, Göteborg, Sweden, and 'Västerås, Sweden
}

SUMMARY Changes in astigmatism during development were studied in 299 infants with astigmatism as they grew from 1 to 4 years of age. All consecutive cases of 1-year-old infants with an astigmatism of $1.0 \mathrm{D}$ or more in at least one eye found at an ophthalmic screening survey were selected for follow-up. The cycloplegic refraction was longitudinally followed at yearly intervals. During development there was no decrease in the degree of hypermetropia, but there was a significant decrease in the incidence and amount of astigmatism during the test period. The most pronounced decrease in magnitude and incidence of astigmatism occurred between the first and second year of life. The majority of astigmatic eyes of the 1-year-old infants had a horizontal curvature greater than the vertical (plus cylinder axis of $180^{\circ}$ ), and no changes of the axis of the astigmatism were noted during the following years.

Recent studies have shown that the incidence of astigmatism differs between infants and schoolchildren. ${ }^{2}$ The high incidence of astigmatism in infancy and the much lower incidence in schoolchildren implies that much of the early astigmatism must be eliminated between the age of 1 and 6 years. Knowledge of the changes in astigmatism that take place during this period is required in order to understand the connection between astigmatism, spherical refraction, squint, and amblyopia.

The aim of this longitudinal study was to follow a population sample of astigmatic infants during a period of four years in order to evaluate the developmental changes of their astigmatism. It is now well documented by both retinoscopy ${ }^{1-3}$ and photorefraction $^{45}$ that infants show a high percentage of astigmatism during the first year of life. Most of the astigmatism cases found during the first year of life have a plus cylinder axis of $180^{\circ}$. Schoolchildren at 6 years of age have a much lower incidence of astigmatism and almost exclusively a plus cylinder axis of $90^{\circ}$. $^{\circ}$ Atkinson et al. ${ }^{7}$ reported that the incidence of astigmatism has declined to the level of the schoolchildren at the age of 18 months, while Mohindra and Held ${ }^{\times}$reported a high incidence as late as 5 years of age.

In the present study we found that the number of

Correspondence to Maths Abrahamsson, Department of Ophthalmology, Sahlgren’s Hospital, S-413 45 Göteborg, Sweden. cases with astigmatism and also the magnitude of the astigmatism decreased between 1 and 2 years of age. This was especially marked in those patients who lost all astigmatism at the age of 4 . Furthermore, we found no change in the axis of astigmatism in any case from the age of 1 to 4 years.

\section{Materials and methods}

All parents in the city of Västerås (population $110000)$ in Sweden are given information at the Children's Health Care Centre of a voluntary ophthalmic screening when the child is about 1 year of age. The ophthalmological control consists of an assessment of motility and alignment as well as cycloplegic retinoscopy. Nearly $50 \%$ of the children born in the city take part in the ophthalmic screening.

During a three-year period approximately 2200 infants were examined. Patients with an astigmatism of $1 \mathrm{D}$ or more and without strabismus or ocular disease were selected for analysis and follow-up. Some of the children were lost in the yearly follow-up and were excluded from the study. Thus 299 cases with an astigmatism of $1 \mathrm{D}$ or more in at least one eye remained through the whole study.

All refractions were written with a plus cylinder convention. The vertical curvature of the eye was considered greater than the curvature of the horizontal meridian if the plus cylinder axis was $90 \pm 15^{\circ}$ 
(with-the-rule astigmatism), and smaller if the axis was $180 \pm 15^{\circ}$. The spherical equivalent was defined as the algebraic sum of the spherical power of the lens system and half the power of the cylinder.

The children were refracted by a Heyne retinoscope 30 minutes after instillation of cyclopentolate $(1 \%)$ by Lindner's method ${ }^{y}$ of cylindersciascopy. The refraction procedure was repeated once a year and the follow-up period was four years.

Spectacles were prescribed for part-time use if the children had an astigmatism $>1.0 \mathrm{D}$ or ametropia $>3 \mathrm{D}$ at the age of 3 years. The cylindrical refraction was then corrected. Spectacles were prescribed for full-time use if any of the refractions showed an anisometropia $\geqslant 1.0 \mathrm{D}$. The anisometropia was then fully corrected.

\section{Results}

The astigmatic children were refracted on four occasions with an interval of one year, and the majority of cases showed a compound hyperopic astigmatism. Ten cases were myopic in both the horizontal and vertical meridian. The refraction values, represented by the spherical equivalent, are presented in Fig. 1. The distribution is bell-shaped with a maximum around $+1 \cdot 0 \mathrm{D}$. The spread of the curve decreased slightly between the age of 1 and 2 years and then remained constant. There was no decrease in hypermetropia, that is, there was no evidence for an age induced peak shift of the distribution.

Fig. 2A shows the astigmatism data. A pronounced change in the amount and incidence of astigmatism occurs between 1 year of age and later. Although we selected patients with an astigmatism $\geqslant 1.0 \mathrm{D}$ at
1 year of age, there were a few cases with an astigmatism of 0.5 (Fig. 2). The reason was that we selected patients with an astigmatism $\geqslant 1.0 \mathrm{D}$ in at least one eye and we used only the right eyes for the calculations. The selection criterion was in these cases fulfilled by the other eye. Between the first and second measurement the astigmatism vanished in one-sixth of the infants. At the age of 4 one-third of the patients had a purely spherical refraction. There was a general shift of the distribution towards lower astigmatic values through the test period, although there were some cases with high cylindrical refractive errors $(\geqslant 2.5 \mathrm{D})$ both at the beginning and at the end of the test period.

The axis of the majority of the astigmatic infants $(n=272)$ was plus cylinder axis $180 \pm 15^{\circ}$, and it remained unchanged during the follow-up period. At the age of 1 there were 18 cases with astigmatism axis in $90 \pm 15^{\circ}$ and 10 cases with oblique axis. No eye showed a variation of the cylinder axis greater than $15^{\circ}$ during the test period.

In $2 \%$ of the infants there was no change in either the amount of cylindrical refraction or in axis during the four years of examination.

The findings on the astigmatism of the 18 cases with axis in $90 \pm 15^{\circ}$ are presented in Fig. 2B. The age induced changes in distribution of the astigmatism of this subgroup differ from the data presented in Fig. 2A. The changes in distribution are small and the changes of astigmatism with age are limited. The astigmatism of the cases with oblique axis showed a decrease with age in the majority of cases (Fig. 2C).

In order to evaluate the individual changes in astigmatism during the follow-up period we selected two subgroups for further analysis - one group of patients with an astigmatism $\geqslant 2.0 \mathrm{D}$ at the initial test session $(n=30)$, and another with patients with no
Fig. 1 The distribution of the spherical equivalent at one-year intervals between 1 and 4 years of age.

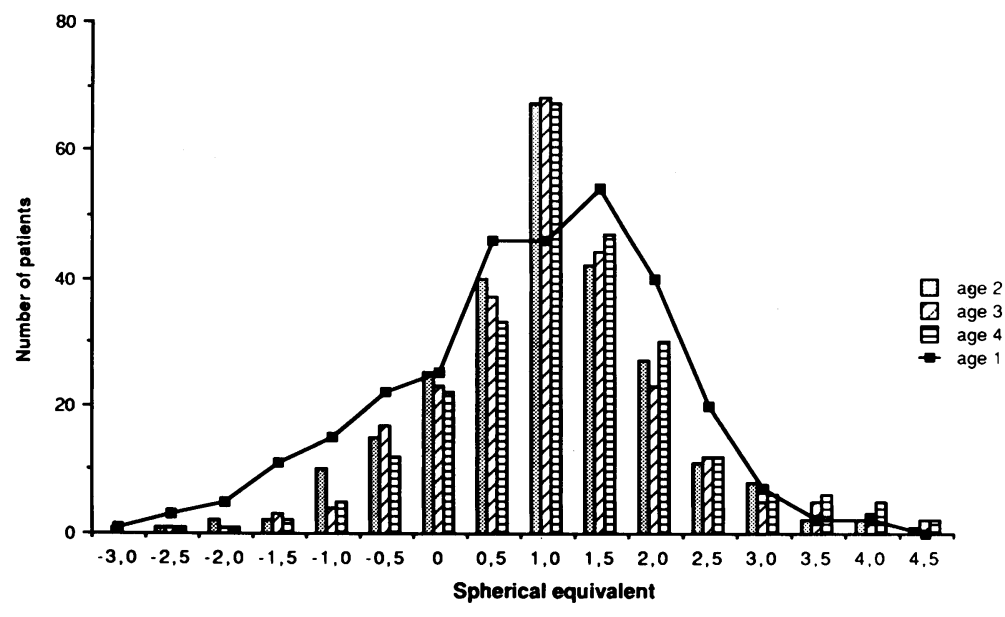


cylindrical errors at the last test session at 4 years $(n=89)$. In general the infants with an initial astigmatism $\geqslant 2 \cdot 0 \mathrm{D}$ showed a decrease of their cylindrical refractive errors at 4 years of age (Fig. 3A). There were, however, some patients (nine out of 49) in this group who had an increasing astigmatism as they grew older. Among them were more infants with a plus cylinder axis of $90^{\circ}$ than would be expected $(n=5)$. Most of the cases in the latter group with no cylindrical error at 4 years had an initial astigmatism of $1.0 \mathrm{D}$, but there were cases with as much as $2.5 \mathrm{D}$ at 1 year of age (Fig. 3B).

$11 \%(n=33)$ of the astigmatic patients had an anisometropia of $1.0 \mathrm{D}$ or more in either meridian at the age of 1 year. At the age of $4,10 \%(n=30)$ had an anisometropia of $1.0 \mathrm{D}$ or more. The majority of cases $(n=19)$ with anisometropia at the age of 1 that showed no anisometropia at the age of 4 were replaced at the measurements at the age of 4 by 16 cases with no anisometropia at the age of 1 year. The anisometropic patients at both age 1 and 4 years were significantly more likely to have an astigmatism of $1.5 \mathrm{D}$ or more, $80 \%(\mathrm{p}<0.001, t$ test $)$ at the age of 1 and $84 \%(\mathrm{p}<0.001, t$ test $)$ at the age of 4 .

When we closely examined the 19 patients who had anisometropia at the age of 1 but not at the age of 4 ,

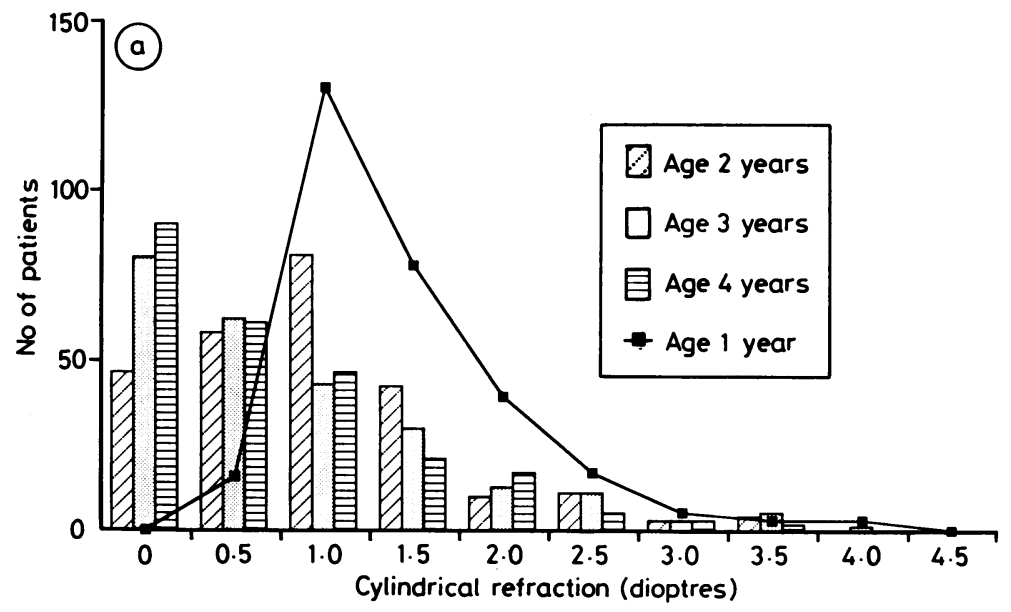

Fig. 2A

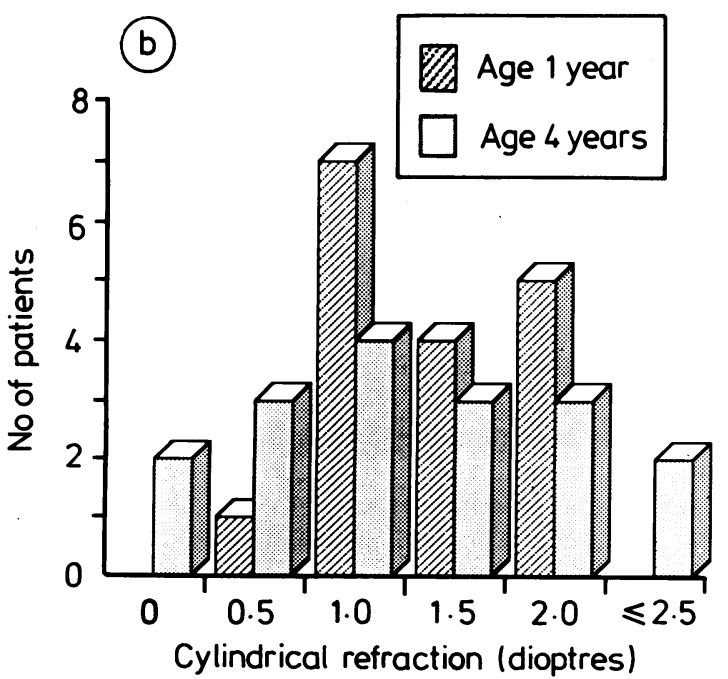

Fig. 2B

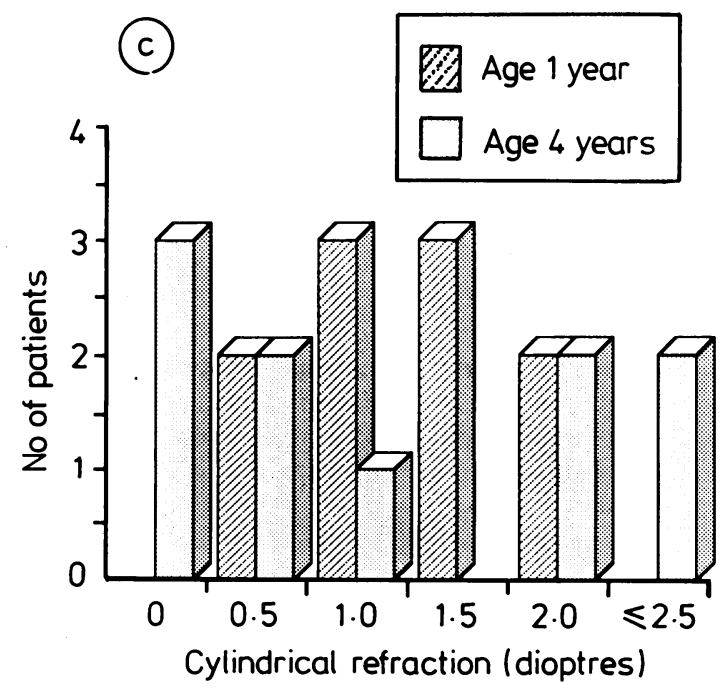

Fig. 2C

Fig. 2 A: Distribution of the cylindrical refractive error at the four-yearly test sessions. In $\mathrm{B}$ and $\mathrm{C}$ the cylindrical refractive power at the age of 1 and 4 years for the patients with with-the-rule astigmatism (B) and oblique astigmatism (C) are presented. 


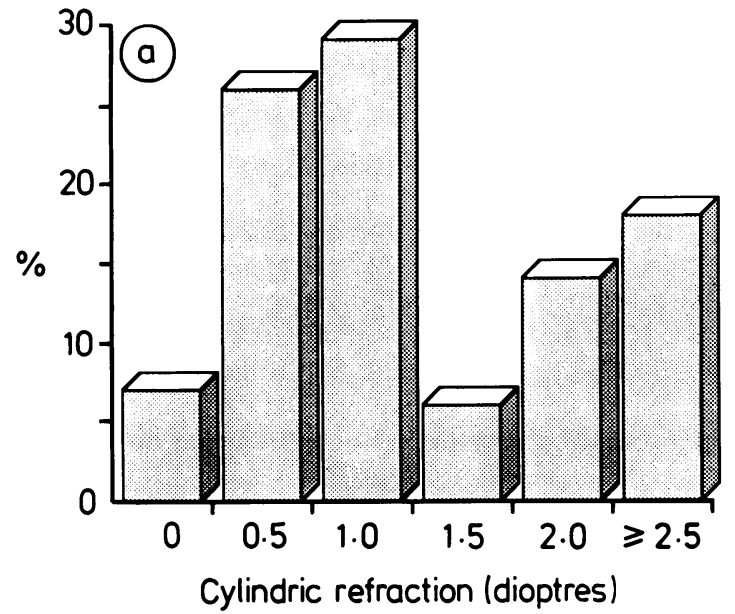

Fig. 3A

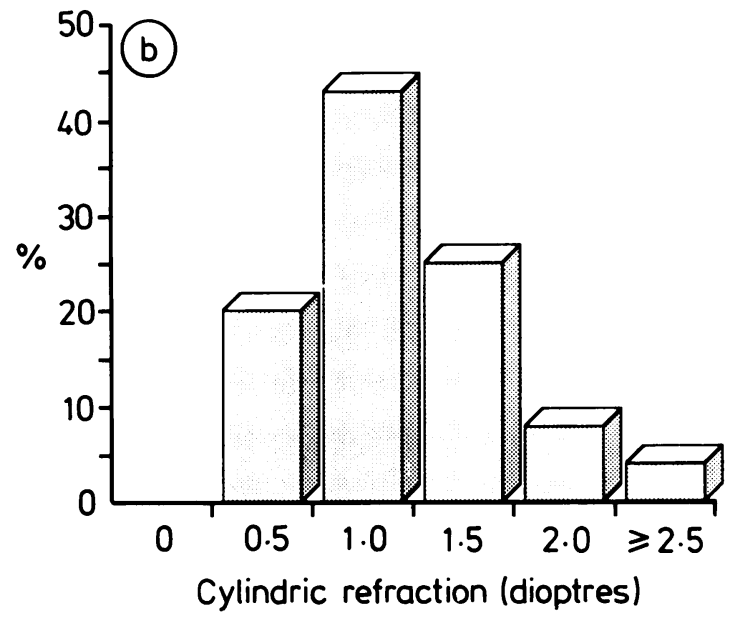

Fig. 3B

Fig. 3 A: Distribution of the cylindrical refraction at the age of 4 years of all infants with a astigmatism $\geqslant 2 \cdot 0 \mathrm{D}$ at the age of 1 year. B: Distribution of the astigmatism at the initial measurement at 1 year of age of all children with disappearance of astigmatism at the age of 4 years.

we found that there was an emmetropisation as well as a conversion of astigmatism to spherical refraction. The magnitude of these two processes is greatest in the most hyperopic eyes. In the 16 patients who had anisometropia that did not show up until the age of 4 there was emmetropisation but no conversion of astigmatism to spherical refraction. This group had, in general, a more hyperopic spherical equivalent refraction than the total sample.

\section{Discussion}

The present study provides longitudinal data on the change in cylindrical refractive power and axis of astigmatism during infancy and early childhood. Our data are in agreement with those of previous studies $^{3710}$ in that the astigmatism decreases as the infant grows older. This change is especially notable in the amount and incidence of astigmatism between the first and second year of life.' During the same period the spread of the distribution of the spherical equivalent is markedly reduced. These results agree with Fabian's theory" of emmetropisation. It is notable that, although there is a continuous reduction of astigmatism throughout the test period, there are only small changes in the distribution of the spherical equivalent after the second year of life. The cylindrical refractive error must be converted into a spherical refractive error.

In infants the predominant form of astigmatism is plus cylinder axis of $180 \pm 15^{\circ}$ as shown in this study for about $90 \%$ of the eyes, whereas after the age of 6 the predominant form is plus cylinder at $90 \pm 15^{\circ} .^{2}$ In our data no evidence for changes in axis with age was found, indicating that the axis remains constant. To our knowledge there is no longitudinal study which shows a change in axis with age, while there are crosssectional data ${ }^{2}$ demonstrating an increasing number of with-the-rule astigmatism (cylindrical axis of $90^{\circ}$ ) and a decreasing number of cases with against the rule astigmatism as the children grow older.

To explain this we need to study the selection criteria. In our longitudinal study infants who had astigmatism at the initial test session were followed up. In this group there is a decreasing incidence of astigmatism and no axis changes during the follow-up period. The probable conclusion from the results of our study is that the astigmatic cases with plus cylinder axis of $90^{\circ}$ found at school age are probably children who acquire their astigmatism at the age of 3 or 4 or later. To examine this phenomenon more closely a longitudinal study must be performed with a large sample of children who are unselected with respect to their refractive status at the beginning of the study.

An important finding in both the group with withthe-rule astigmatism and the group with oblique astigmatism was that there are cases with an increasing astigmatism as well as an increasing spherical equivalent refraction with age. This phenomenon was not found in the group with against-the-rule astigmatism. This indicates that patients with withthe-rule and oblique astigmatism at the age of 1 year need a special follow-up.

In agreement with the data presented by Ingram and Barr $^{12}$ we found an association between aniso- 
metropia and astigmatism and that approximately $50 \%$ of the anisometropic cases are exchanged during follow-up. This relation was significant at both the age of 1 and 4 years. It is important to note that the subgroups with anisometropia in combination with astigmatism are unstable.

In summary, our study showed that dynamic changes occur in astigmatism and anisometropia during infancy. Although the majority of cases show a decrease in magnitude of astigmatism between 1 and 4 years, some children show an astigmatism that is stationary or even increasing.

The special subgroups of astigmatic eyes at risk of amblyopia or squint or both must be studied further, and the instability of astigmatism and anisometropia have to be taken into consideration before spectacles are prescribed for very young children.

This work was supported by Swedish Medical Research Council (grant 02226), the Samaritan Foundation, and the handlanden H. Svensson foundation.

\section{References}

1 Mohindra I, Held R, Gwiazda J, Brill S. Astigmatism in infants. Science 1978; 202: 329-30.
2 Gwiazda J, Scheiman M, Mohindra I, Held R. Astigmatism in children: changes in axis and amount from birth to 6 years. Invest Ophthalmol Vis Sci 1984; 25: 88-92.

3 Fulton AB, Dobson Y, Salem D, Mar C, Petersen RA, Hansen RM. Cycloplegic refraction in infants and young children. $A m J$ Ophthalmol 1980; 90: 239-47.

4 Howard HC. Infant eyes: optics and accommodation. Curr Eye Res 1982; 2: 217-24.

5 Howland HC, Atkinson J, Bradick O, French J. Infant astigmatism measured by photorefraction. Science 1978; 202: 331-2.

6 Hirsch MJ. Changes in astigmatism during the first eight years of school: an interim report from the Ojuai longitudinal study. $A m J$ Optom 1963; 40: 127-32.

7 Atkinson J, Bradick O, French $J$. Infant astigmatism: its disappearance with age. Vision Res 1980; 40: 891-3.

8 Mohindra I, Held R. Refraction in humans from birth to 5 years. Doc Ophthalmol Proc Ser 1981; 28: 19-27.

9 Lindner G. Die Bestimmungen des Astigmatismus durch die Schatteprobe mit Zylindergläsern. Berlin: Karger, 1927.

10 Dobson V, Fulton AB, Sebris SL. Cycloplegic refraction of infants and young children: the axis of astigmatism. Invest Ophthalmol Yis Sci 1984; 25: 83-7.

11 Fabian G. Ophthalmological serial examination of 1200 children in the second year of life. Acta Ophthalmol (Kbh) 1966; 49: 473-9.

12 Ingram RM, Barr A. Changes in refraction between the ages of 1 and 31/2 years. BrJ Ophthalmol 1979; 63: 339-42.

Accepted for publication 4 December 1986. 